\title{
Combined effect of ultraviolet radiation and application of acetic acid on the quality of guinea pig meat and increased of its shelf life
}

\begin{abstract}
The aim of this research was to determine the effect of the combination of ultraviolet radiation (UVR) and acetic acid (AA) on the quality of guinea pig meat and the increasing of its shelf life. 90 weaned guinea pigs of 14 days old on average were used. A $3 \times 3$ Factorial Design was used, 9 treatments with 5 repetitions and 2 animals per repetition, considering: Factor 1: UV radiation time $(0,5$ and 10 minutes) and Factor 2: Acetic acid concentration $(0,2$ and $4 \%)$. A total of 45 experimental units were analyzed. The parameter evaluated was meat quality: nutritional, microbiological, physical, chemical and organoleptic characteristics. For this research, it was used the statistical program SAS (Statistical Analysis System) using Duncan's mean comparative test to analyze the variance of the data and differences between treatments. Friedman test and Scalar difference test were used to evaluate the sensory analysis. The ultraviolet radiation combined with acetic acid enhances the antimicrobial activity and improves the quality of guinea pig meat, increasing its shelf life as this was observed in the combined treatments with 5 and 10 minutes of UVR with $2 \%$ and $4 \%$ of AA. The protein, ethereal extract, ashes and nitrogen-free extract of guinea pig meat were not altered in the 9 treatments by the application of UVR and AA. The moisture and dry matter of guinea pig meat are maintained with the application of UVR and AA and the organoleptic characteristics (smell, color, taste, juiciness and, texture) of the meat were not altered by the application of UVR and AA, being the treatment with $10^{\prime} \mathrm{UV}+4 \% \mathrm{AA}$, which presented the greatest preference, compared with $10^{\prime} \mathrm{UV}+0 \%$, both did not show any microbial load but $10^{\prime} \mathrm{UV}+4 \%$ presented much preference than $10^{\prime} \mathrm{UV}+0 \% \mathrm{AA}$. There was no statistical difference between treatments. In conclusion, the combination of acetic acid and UV radiation enhanced the quality and preference of guinea pig meat being the best treatment evaluated $10^{\prime} \mathrm{UV}+4 \% \mathrm{AA}$.
\end{abstract}

Keywords: guinea pig, uv radiation (UVR), acetic acid (aa), meat quality, shelf life
Volume 6 Issue I - 2018

\author{
Jorge Guevara,' Leoncio Reyna,' Alberth \\ Pedemonte, ${ }^{2}$ Rodolfo Vergaray, ${ }^{2}$ Jorge \\ Pachas $^{2}$ \\ 'Department of Zootechnics, San Marcos Major National \\ University, Peru \\ ${ }^{2}$ School of Agro industrial Engineering, San Marcos Major \\ National University, Peru
}

\begin{abstract}
Correspondence: Jorge Guevara, Professors of the Faculty of Chemistry and Chemical Engineering, Department of Zootechnics, San Marcos Major National University, Peru, Emailguevaravet@hotmail.com
\end{abstract}

Received: November 15, 2017 | Published: February 20, 2018

\section{Introduction}

Food can contain different kind of spoilage agents coming from natural sources, environmental contamination or those incorporated during their production or transformation, in some cases, causing diseases, which are called foodborne illness. Meat is a matrix rich in nutrients that provide an adequate environment for the proliferation of various microorganisms, spoilage, and pathogens microorganisms, within this group are E. coli O157 and non-E. coli-O157, Salmonella spp. and Listeria monocytogenes. Food preservation methods aim to increase the shelf life of products during storage, ideally by applying techniques that prevent microbiological alterations while maintaining quality. ${ }^{1,2}$ That is why today technologies have been created that achieve this goal; among them the UV radiation stands out, defined as; "Absorption by atoms and molecules produces joint breaks and ion formation." Nowadays UV radiation is used in different sectors of the food industry, due to the harmful effect it causes on the DNA of many microorganisms. Also, it is chosen because it is a process which does not alter the organoleptic properties of the products and reduces the use of chemical substances. It is used for the preservation of liquid and solid foods, but in solid food, this application is effective at the surface. $^{3}$

The use of UV technology for disinfection purposes involves the ultraviolet region of the electromagnetic spectrum, with a wavelength range between 100 and $400 \mathrm{~nm}$. This can be subdivided into: UV short-wave (UV-C) between 200 and $280 \mathrm{~nm}$, germicidal range. UV wave medium (UV-B) between 280 and $315 \mathrm{~nm}$ and UV long wave (UV-A) between 315 and 400nm. Acetic acid is a natural chemical that is found in apples, cheese, cocoa, grapes, milk, oranges, parsley, peaches, pineapples, raspberries, strawberries and berries. The vinegar is approximately $5 \%$ acetic acid. As a GRAS substance, it is often used as a flavoring agent, in the pickling process and to control acidity in processed foods. ${ }^{4}$ The shelf life or expiration of a food can be defined as "the period of time, after processing and/or packaging and under certain storage conditions, in which the food remains safe and suitable for consumption", in other words during this time, it must conserve its physical-chemical, microbiological and sensory characteristics, as well as its nutritional and functional characteristics. ${ }^{5}$ The aim of this research was to determine the effect of the combination of UV radiation and acetic acid on the quality of guinea pig meat and the increasing of its shelf life. ${ }^{6}$

\section{Material and methods}

The present research was conducted at San Marcos Major National University (Lima, Peru) in a research farm, especially prepared for the development of this study. 90 guinea pigs of 14days old on average were used, which were distributed in 9 treatment and 5 repetitions per treatment, where each repetition consisted of 2 animals. ${ }^{7}$ 
a) Guinea Pigs: The animals were placed in the guinea pig research farm, twenty-four cages of $0.5 \mathrm{~m}$ long by $0.5 \mathrm{~m}$ wide and $0.37 \mathrm{~m}$ high were used, with one clay feeder and one clay drinking trough per cage. A digital scale model SF-400 of 0 to $7000 \mathrm{~g}$ was used to control weekly the weight of the animals during 8 weeks. ${ }^{8}$

b) Ultraviolet Radiation: One UVC-low pressure lamp of $15 \mathrm{~W}$ model PHILIPS G15T8 was used in an experimental module. The distance between the lamp and the guinea pig meat was $24 \mathrm{~cm}$ for all treatments.

c) Acetic acid: White vinegar from a local brand "Del Firme", with $\mathrm{pH} 2.3+/-0.20$ was used. The different treatments were calculated on the percentage of the vinegar.

\section{Treatments}

9 treatments were evaluated, which are described below:

T1: UV rays for $0 \mathrm{~min}$ and $0 \%$ acetic acid; T2: UV rays for $0 \mathrm{~min}$ and $2 \%$ acetic acid

T3: UV rays for $0 \mathrm{~min}$ and $4 \%$ acetic acid; T4: UV rays for $5 \mathrm{~min}$ and $0 \%$ acetic acid

T5: UV rays for $5 \mathrm{~min}$ and $2 \%$ acetic acid; T6: UV rays for $5 \mathrm{~min}$ and $4 \%$ acetic acid

T7: UV rays for $10 \mathrm{~min}$ and $0 \%$ acetic acid; T8: UV rays for $10 \mathrm{~min}$ and $2 \%$ acetic acid

T9: UV rays for $10 \mathrm{~min}$ and $4 \%$ acetic acid.

\section{Parameters evaluated}

$$
\begin{aligned}
\text { i. } & \text { Physical analysis } \\
\text { ii. } & \text { Chemical analysis } \\
\text { iii. } & \text { Microbiological analysis } \\
\text { iv. } & \text { Sensory evaluation }
\end{aligned}
$$

\section{Experimental design}

A 3x3 Factorial Design 9 treatments with 5 repetitions each one, 2 animals per repetition was used, considering: Factor 1: UV radiation time ( 0,5 and 10minutes), Factor 2: Acetic acid concentration $(0,2$ and 4) \%). A total of 45 experimental units were conducted.

\section{Analysis of data}

The data were analyzed using the SAS program. Duncan's test was used to compare the averages and for the tasting test was used the Scalar difference test, Friedman test, ANVA and Tukey test.

\section{Results and discussions}

\section{Physical analysis}

Table 1 represents the result of the proximal physical analysis of guinea pig meat. Nine treatments were tested.

A. Moisture: The meat of the guinea pig that received 10minutes of ultraviolet radiation without acetic acid (10'UV+0\% AA) presented the highest percentage of moisture with $71.21 \%$, followed by the meat of the guinea pig of the treatment 5 ' $U V+2 \%$ AA with $70.99 \%$ and the lowest percentage of moisture was presented by the meat of the guinea pig with 0 'UV $+0 \%$ AA.
B. Dry matter: The meat of the guinea pig that received 0 ' $U V+0 \%$ AA presented the highest percentages of dry matter, known as dry weight which represents its solids excluding water, with $40.51 \%$, followed by the meat of the guinea pig that received 5 ' $U V+0 \%$ AA with $37.05 \%$ and the lowest percentages of dry matter was presented by the meat of the guinea pig that received 10 ' $U V+0 \%$ AA with $28.79 \%$ (Table 1 ).

Table I Proximate physical analysis of guinea pig meat (*)

\begin{tabular}{lll}
\hline Treatment & Moisture & Dry matter** \\
\hline 0'UV+0\%AA & 59.49 & 40.51 \\
0'UV+2\%AA & 66.81 & 33.19 \\
0'UV+4\%AA & 69.29 & 30.71 \\
5'UV+0\%AA & 62.95 & 37.05 \\
5'UV+2\%AA & 70.99 & 29.01 \\
5'UV+4\%AA & 70.05 & 29.95 \\
I0'UV+0\%AA & 71.21 & 28.79 \\
I0'UV+2\%AA & 66.58 & 33.42 \\
I0'UV+4\%AA & 66.2 & 33.8 \\
\hline
\end{tabular}

*The values correspond to the average of three samples per treatment **Dry matter plus moisture equal a hundred percent

\section{Chemical analysis}

The results of the proximal chemical analysis of guinea pig meat from different treatments are shown in Table 2. The amount of protein, ether extract and nitrogen-free extract on average is maintained with the application of UVR but decreases with increasing the percentage of AA application. Also, number of ashes is maintained with the application of both UVR and AA (Table 2). It can be seen that the best percentages of protein (17.65\%), ethereal extract $(13.63 \%)$ and ashes $(1.38 \%)$ were for the meat of the guinea pigs that received 0 'UV $+0 \%$ AA, being the lowest percentage of protein $(14.02 \%)$ and ashes $(0.71 \%)$ for the meat of the guinea pigs that received 5 ' $U V+2 \%$ AA and the lowest percentage in ethereal extract (7.82\%) was for the meat of the guinea pigs that received 10 'UV $+0 \% \mathrm{AA}$. In nitrogen-free extract, the highest percentage $(7.88 \%)$ was presented by the meat of the guinea pigs that received 5 ' $\mathrm{UV}+2 \% \mathrm{AA}$, followed by the meat that received $10^{\prime} \mathrm{UV}+0 \%$ AA with $7.85 \%$ and the lowest percentage of nitrogen-free extract was presented by the meat of the guinea pigs that received 5'UV+4\% AA with 5.58\%.

\section{Sensory evaluation}

Organoleptic characteristics: The information on organoleptic characteristics of guinea pig meat is shown in Table 3. The tasting panelists familiar with guinea pig meat gave as consensus, guinea pig meat samples which ones received 5'and 10' of UVR+AA, had an excellent color, smell, taste and juiciness obtaining the best qualifications. Likewise, texture remains the same in all treatments. When performing the statistical analysis of the results, it was observed that there is no significant difference between the samples on the organoleptic characteristics of guinea pig meat that received different experimental diets (treatments) (Table 3 ). When we analyzed the surveys templates done by trained tasters and familiar with the consumption of guinea pig meat, it was found the color, smell, taste, 
juiciness and texture of the guinea pig meat where the UVR and AA were applied, were not altered and had the best preference, this shows

Table 2 Proximate chemical analysis of guinea pig meat $(*)$ that the application of UVR and AA to guinea pig meat does not affect its organoleptic characteristics.

\begin{tabular}{lllllllll}
\hline \multirow{2}{*}{ Treatment } & \multicolumn{3}{l}{ Protein(\%) } & \multicolumn{2}{l}{ Ethereal extract(\%) } & \multicolumn{2}{c}{ Ash(\%) } & \multicolumn{2}{c}{ Nitrogen-free extract(\%) } \\
\cline { 2 - 8 } & Wet & Dry & Wet & Dry & Wet & Dry & Wet & Dry \\
\hline 0'UV+0\%AA & 17.65 & 43.34 & 13.63 & 34.07 & 1.38 & 3.39 & 7.85 & 19.2 \\
0'UV+2\%AA & 13.16 & 39.61 & 13.35 & 40.58 & 0.91 & 2.73 & 6.1 & 17.09 \\
0'UV+4\%AA & 15.13 & 49.27 & 8.95 & 29.10 & 1.01 & 3.30 & 5.62 & 18.34 \\
5'UV+0\%AA & 16.04 & 43.09 & 12.04 & 32.20 & 1.20 & 3.27 & 7.77 & 21.45 \\
5'UV+2\%AA & 14.02 & 48.34 & 9.40 & 22.19 & 0.71 & 2.45 & 7.88 & 27.02 \\
5'UV+4\%AA & 14.75 & 49.26 & 8.72 & 29.10 & 0.90 & 2.99 & 5.58 & 18.65 \\
I0'UV+0\%AA & 16.65 & 40.38 & 11.82 & 26.56 & 0.96 & 2.67 & 8.56 & 30.39 \\
I0'UV+2\%AA & 15.07 & 45.10 & 10.31 & 30.97 & 1.01 & 3.01 & 7.03 & 20.92 \\
I0'UV+4\%AA & 14.88 & 43.88 & 10.63 & 34.66 & 0.83 & 2.42 & 6.47 & 19.04 \\
\hline
\end{tabular}

*The values correspond to the average of three samples per treatment

Table 3 Organoleptic characteristics of guinea pig meat of different treatments

\begin{tabular}{llllll}
\hline Treatment & Color & Smell & Taste & Juiciness & Texture \\
\hline 0'UV+0\%AA & 2.63 & 3.38 & 2.63 & 2.63 & 2.63 \\
0'UV+2\%AA & 2.88 & 2.75 & 2.63 & 2.63 & 3.00 \\
0'UV+4\%AA & 3.13 & 3.13 & 3.13 & 3.00 & 3.00 \\
5'UV+0\%AA & 2.88 & 3.38 & 3.00 & 3.25 & 3.25 \\
5'UV+2\%AA & 3.50 & 3.50 & 3.13 & 2.75 & 2.88 \\
5'UV+4\%AA & 3.13 & 3.38 & 3.13 & 3.13 & 3.00 \\
I0'UV+0\%AA & 3.38 & 3.38 & 3.13 & 3.00 & 3.13 \\
I0'UV+2\%AA & 2.88 & 3.38 & 3.38 & 3.25 & 3.38 \\
I0'UV+4\%AA & 3.38 & 3.75 & 3.88 & 3.38 & 3.38 \\
\hline
\end{tabular}

Preference degree for guinea pig meat: Table 4 shows the preference degree for guinea pig meat of different treatments. The panelists showed much preference with $62.5 \%$ for guinea pig meat that received 10 ' $\mathrm{UV}+4 \% \mathrm{AA}$, then preference with $62.5 \%$ for guinea pig meat that received 10 'UV $+2 \%$ AA, they showed little preference for meat that received 0 ' $U V+2 \% \mathrm{AA}$ and no preference for meat that received neither UVR nor AA ( 0 'UV $+0 \% \mathrm{AA})$. When performing the statistical analysis of the results, referring to the preference for the meat of guinea pigs from different treatments, it was observed, there were no significant differences between the samples on the preferences of guinea pig meat that received the different experimental diets. The tasters showed a lot of preference for guinea pig meat where UVR and AA were applied, which indicates a high degree of satisfaction of the panelists for the guinea pig meat that received the longest UV application time combined with the highest AA percentage (Table 4). ${ }^{9}$

Table 4 Preference degree for guinea pig meat of different treatments*

\begin{tabular}{lllll}
\hline \multirow{2}{*}{ Treatment } & Much preference & Preference & Little preference & No preference \\
\cline { 2 - 5 } & $\%$ & $\%$ & $\%$ & $\%$ \\
\hline 0'UV+0\%AA & 0 & 37.5 & 37.5 & 25 \\
0'UV+2\%AA & 12.5 & 25.0 & 62.5 & 0 \\
0'UV+4\%AA & 25.0 & 62.5 & 12.5 & 0 \\
5'UV+0\%AA & 50.0 & 0 & 50.0 & 0 \\
5'UV+2\%AA & 25.0 & 62.5 & 12.5 & 0 \\
5'UV+4\%AA & 37.5 & 50.0 & 12.5 & 0 \\
I0'UV+0\%AA & 37.5 & 62.5 & 0 & 0 \\
I0'UV+2\%AA & 37.5 & 62.5 & 0 & 0 \\
I0'UV+4\%AA & 62.5 & 37.5 & 0 & 0 \\
\hline
\end{tabular}

*Each treatment was evaluated by the same 8 panelists 
Microbiological analysis of guinea pig meat: The result of the microbiological analysis is shown in Table 5 and Figure 1. It is appreciated that there was no growth of colonies in MacConkey agar, that is to say, there was no presence of microbial load, in the same way in Nutritive agar in the treatments with 0 ' $U V+4 \% \mathrm{AA}, 5^{\prime} \mathrm{UV}+2 \% \mathrm{AA}$, $5^{\prime} \mathrm{UV}+4 \%$ AA, $10^{\prime} \mathrm{UV}+0 \% \mathrm{AA}, 10^{\prime} \mathrm{UV}+2 \%$ AA and $10^{\prime} \mathrm{UV}+4 \% \mathrm{AA}$. The highest microbial load was presented by the meat of the treatments with 0 'UV $+0 \% \mathrm{AA}$. There is a difference between the treatments with 0 'UV $+2 \% \mathrm{AA}$ and 0 'UV $+4 \% \mathrm{AA}$, where the treatment with a major percentage of AA do not show microbial load likewise 5'UV+0\%AA and 5 'UV+2\%AA. There was no presence of a microbial load in the combined action of UVR and AA in 5'UV and 10'UV with 2\%AA and $4 \% \mathrm{AA}$, with an exception of the treatment $10^{\prime} \mathrm{UV}+0 \% \mathrm{AA}$ which is the longest UVR time evaluated, this indicates that the application of UVR and AA on guinea pig meat inhibits bacterial growth, decreasing the microbial load on the surface. The UV-C radiation $(254 \mathrm{~nm})$ has an important bactericidal action and on the other hand, its use is proposed to produce a beneficial effect in the tissues in response to low or sublethal doses according to the concept of "hormesis". ${ }^{10}$ UV-C radiation is emerging as one of the technologies with greater application in the future, Cisneros-Zevallos ${ }^{11}$ suggests the postharvest application of a type of controlled abiotic stress (for example exposure to UV-C light) to induce production and increase of the synthesis of photochemical compounds with nutraceutical activity or the reduction of undesirable compounds. Thus, stress control induced by UV-C light can be used as a tool to reinforce the beneficial properties of fresh products, whole or cut products. ${ }^{12}$ Ultraviolet radiation combined with acetic acid enhances its antimicrobial activity, as observed in the results presented in this research.

Table 5 Microbial load on guinea pig meat

\begin{tabular}{|c|c|c|}
\hline \multirow{2}{*}{ Treatment } & \multicolumn{2}{|c|}{ Plate count (CFU/mL) } \\
\hline & Nutritive agar & Macconkey agar \\
\hline $0 ' \mathrm{UV}+0 \% \mathrm{AA}$ & $9.00 \mathrm{E}+04$ & \\
\hline $0 ' U V+2 \% A A$ & $2.00 \mathrm{E}+04$ & \\
\hline 0'UV+4\%AA & $0.00 \mathrm{E}+00$ & \\
\hline $5 ' U V+0 \% A A$ & $1.00 \mathrm{E}+04$ & \\
\hline $5 ' U V+2 \% A A$ & $0.00 \mathrm{E}+00$ & 0 \\
\hline $5^{\prime} \mathrm{UV}+4 \% \mathrm{AA}$ & $0.00 \mathrm{E}+00$ & \\
\hline IO'UV+0\%AA & $0.00 \mathrm{E}+00$ & \\
\hline $10^{\prime} U V+2 \% A A$ & $0.00 \mathrm{E}+00$ & \\
\hline I0'UV+4\%AA & $0.00 \mathrm{E}+00$ & \\
\hline
\end{tabular}

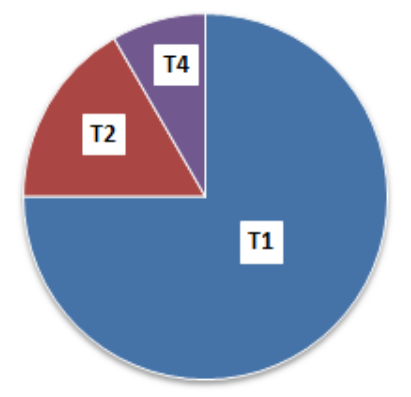

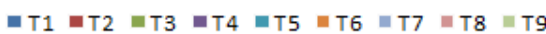

Figure I Microbial load on nutritive agar per treatment.

\section{Conclusion}

At the end of this research work, the following conclusions were reached:

A. Ultraviolet radiation combined with acetic acid enhances its antimicrobial activity and improves the quality of guinea pig meat, increasing its shelf life.

B. The chemical and physical characteristics of guinea pig meat were not altered by the application of UV radiation and acetic acid.

C. The organoleptic characteristics (smell, color, taste, juiciness and texture) of the meat were not altered by the application of UVR and AA. The degree of preference was greater for the guinea pig meat that received the application $10{ }^{\prime} \mathrm{UV}+4 \% \mathrm{AA}$. The best treatment evaluated in this research was $10^{\prime} \mathrm{UV}+4 \%$. This treatment did not present changes in its chemical and physical characteristics did not show any microbial load and it had the greatest preference by the panelist.

\section{Recommendations}

We recommend carrying out this research in meats for human consumption derived from other minor animals. Implement this method of increasing the quality of the meat in companies producing and industrializing guinea pig meat.

\section{Acknowledgements}

None.

\section{Conflict of interest}

Author declares that there is no conflict of interest.

\section{References}

1. Forsythe J, Hayes R. Food hygiene, microbiology and HACCP. 3rd ed. USA: Springer; 2002. p. 1-472.

2. Garcia FI. Safe food: Basic guide on food security. Spain: Ediciones Diaz De Santos; 2011. p. 1-172.

3. Dominguez L. Ultraviolet Light in Food Technology: Principles and Applications. USA: CRC Press; 2010. p. 1-296.

4. Harte J, Holdren C, Schneider R, et al. Toxics A to Z: Guide to Everyday pollution hazards. USA: University of California Press; 1991. p. 1-576.

5. Brennan J. Manual of food processing. Editorial ACRIBIA, SA Zaragoza, Spain; 2008.

6. Calderon G, Raybaudi M, Mosqueda M, et al. Effect of uv-c light and malic acid on populations of Rhodotorula glutinis and shelf life of papaya maradol slices. Bioagro. 2012;24(2):103-114.

7. Chauca L, Higaonna R, Muscari J. Management of guinea pigs. Ministry of Agriculture. Technical Bulletin; 2004:1-47.

8. Perez R. Fish silage for feeding livestock. USA: Food and Agriculture Organisation; 1998.

9. Guevara JV, Sergio RM, Fernando CC, et al. Enrichment of guinea pig meat with omega-3 fatty acids by supplementing diets with fish oil and sacha inchi seeds. Rev Investig Vet Peru. 2015;27(1):45-50.

10. Ruiz G, Questa A, Rodriguez S. Effect of uv-c light on the antioxidant properties and sensory quality of minimally processed cabbage. Rev Ibereroamer Tecnol Postcosecha. 2010;11(1):101-108. 
11. Cisneros Zevallos L. The use of controlled postharvest abiotic stresses as a tool for enhancing the nutraceutical content and adding-value of fresh fruits and vegetables. J Food Sci. 2003;68(5):1560-1565.
12. Andrade M, Moreno C, Henriquez A, et al. Influence of UV-C radiation as a post-harvest treatment on carambola (Averroha carambola L.) minimally processed stored in refrigeration. Rev Iber Tecnologia Postcosecha. 2010;11(1):18-27. 